\title{
Long-Term Effects of Low-Intensity Exercise Training on Fat Metabolism in Weight-Reduced Obese Men
}

\author{
Dorien P. van Aggel-Leijssen, Wim H. Saris, Gabby B. Hul, and Marleen A. van Baak
}

\begin{abstract}
The aim of the present study was to investigate the effect of long-term continuation of low-intensity exercise training on weight maintenance, substrate metabolism, and $\beta$-adrenergic-mediated fat oxidation in weight-reduced obese men. Preceding this part of the study, subjects lost $15 \pm 6 \mathrm{~kg}$ of body weight by energy restriction with or without low-intensity exercise training. Twenty-nine subjects (diet group, $n=15$; diet + exercise group, $n=14$ ) participated in the follow-up study of 40 weeks in which the former diet + exercise group continued their exercise training program. Pre- and postfollow-up, measurements of body weight, body composition, maximal aerobic capacity and substrate oxidation during rest, exercise, and recovery with or without infusion of the $\beta$-adrenergic antagonist, propranolol (PRP), were performed. Over the follow-up period, body weight, fat mass, and fat free mass increased in both groups $(P<.0001)$ without differences between groups. Attendance at exercise training sessions was negatively correlated with regain of body weight $(r=-.6, P<.05)$. Relative fat oxidation, energy expenditure, and $\beta$-adrenergic-mediated fat oxidation during rest, exercise, and recovery were maintained over the follow-up period in both groups. Continuation of low-intensity exercise training after weight reduction did not limit regain of body weight, unless exercise training was frequently performed. Relative ( $\beta$-adrenergic-mediated) fat oxidation and energy expenditure were maintained at postdiet level whether or not low-intensity exercise training was performed during follow-up.
\end{abstract}

Copyright 2002, Elsevier Science (USA). All rights reserved.

T

HE PREVALENCE OF obesity is increasing in the United States ${ }^{1}$ and Europe. ${ }^{2}$ Obesity is identified nowadays as a serious health problem, which can be treated by energy restriction. Although energy restriction programs are successful on short term, on long term there is a great risk for body weight regain. ${ }^{3-6}$ Addition of exercise training is suggested to be the cornerstone for long-term weight maintenance. ${ }^{7,8}$ Although several studies have shown that addition of exercise training during and after energy restriction limits the regain of body weight on long-term compared with energy restriction only, ${ }^{4,9}$ others found no difference in body weight regain between the diet only (D) and diet plus exercise (DE) group. ${ }^{6,10-13}$ The decreased fat oxidation accompanying a decrease in fat mass due to weight loss ${ }^{11,14}$ is suggested to be involved in the regain of body weight after weight loss. ${ }^{15,16}$ In a first report on the present study, we have shown that low-intensity exercise training (exercise intensity $40 \% \dot{\mathrm{V}}_{2}$ max, 3 to 4 times per week for 12 weeks) in combination with a VLCD (very low calorie diet; $2 \mathrm{MJ} / \mathrm{d}$ ) (DE group) resulted in a weight loss of $15 \pm 6 \mathrm{~kg}$ after 12 weeks, which did not differ from the weight loss in the group only receiving VLCD (D group). ${ }^{17}$ After body weight had stabilized, respiratory exchange ratio (RER) was higher in the $\mathrm{D}$ group than in the DE group in fasting conditions $(\Delta$ $0.04 \pm 0.05 ; P<.05)$ after 45 minutes of exercise at $50 \%$ $\dot{\mathrm{V}}_{\mathrm{O}_{2}} \max (\Delta 0.03 \pm 0.07$; not significant $[\mathrm{NS}])$ and after 15 minutes recovery $(\Delta 0.05 \pm 0.04 ; P<.001)$. Another study reported similar results for RER at rest after 6 months of low-intensity exercise training and energy restriction. ${ }^{11}$ In addition, in our study, some evidence was found for a role of the sympathetic nervous system in preventing the decline in fat oxidation by low-intensity exercise training. ${ }^{17}$ Although lowintensity exercise training added to a VLCD period did not result in increased weight loss within 12 weeks, maintenance of a lower RER can be hypothesized to prevent or limit long-term weight regain. Therefore, this part of the study investigated the effect of continuation of the low-intensity exercise training program for 40 weeks after weight loss on RER, sympathetic nervous system activity, and regain of body weight or fat mass in the exercise group (former DE group) and compared it with changes in the control group (former D group) who did not follow this training program.

\section{MATERIALS AND METHODS}

\section{Subjects}

Thirty-seven obese male subjects (body mass index [BMI] $>27$ $\mathrm{kg} / \mathrm{m}^{-2}$ ) participated in the present study. Baseline body weight was $103 \pm 11 \mathrm{~kg}$. All subjects participated during the 12 weeks preceding this part of the study in an energy restriction program (VLCD; $2 \mathrm{MJ} / \mathrm{d}$ ) (diet period). Twenty subjects also participated in an exercise training program as described below. Results of the diet period have been reported previously. After these initial 12 weeks, subjects were followed during a period of 40 weeks (follow-up period). They were instructed to maintain body weight at the post-VLCD level. The exercise training group continued the same exercise training program. All subjects were in good health as assessed by medical history and physical examination. At baseline, none of the subjects spent more than 2 hours a week in sports activities or had a physically demanding job. They did not take medication known to influence the variables measured. Before the energy restriction program started, subjects were matched with respect to age, BMI, fat percentage, weight, and maximal oxygen uptake and randomly divided in 2 groups, the D or DE. The last 2 weeks of the diet period, subjects stabilized body weight (change during the last week, $+0.17 \% \pm 0.96 \%[0.14 \pm 0.89 \mathrm{~kg}]$ ). On average, weight loss was $15.0 \pm 5.8 \mathrm{~kg}$. The study protocol was approved by the

From the Nutrition, Toxicology and Environmental Research Institute (NUTRIM), Department of Human Biology, Maastricht University, Maastricht, The Netherlands.

Submitted July 24, 2001; accepted February 11, 2002.

Supported by Grant No. 95040 from the Netherlands Heart Association.

Address reprint requests to Dorien van Aggel-Leijssen, PhD, Maastricht University, Department of Human Biology, PO Box 616, 6200 MD Maastricht, The Netherlands.

Copyright 2002, Elsevier Science (USA). All rights reserved. 0026-0495/02/5108-0009\$35.00/0

doi:10.1053/meta.2002.34028 
Ethics Committee of Maastricht University. Written informed consent was obtained from all subjects.

In this part of the study, subjects in the former D group form the control group (C) and subjects in the former DE group form the exercise group (E). Two subjects from the control group did not participate in the measurements after the follow-up period (due to lack of motivation). In the exercise group, 6 subjects did not participate in the final measurements ( 3 due to illness [ 2 knee injuries not related to the training program, 1 nephritis] and 3 due to lack of motivation). Subject characteristics of the remaining study population are shown in Table 1 .

\section{Experimental Design}

In the follow-up period, subjects in the exercise group continued their low-intensity exercise training program. Body weight was measured in both groups every 2 weeks. Before and after the follow-up period, measurements of body composition, maximal aerobic capacity, energy and substrate metabolism at rest, and during exercise with and without administration of a nonselective $\beta$-adrenergic antagonist were performed in both groups.

\section{Exercise Training}

Twenty subjects participated in an exercise training program during the follow-up period of 40 weeks (exercise group [E]). The subjects in the control group (C) were instructed not to change their habitual activity pattern over this period. The subjects in the exercise group trained 4 times 1 hour/week, 3 times at the laboratory under supervision of a professional trainer and once at home. The exercise training program consisted of cycling on an ergometer (Bodyguard Cardiocycle; Sandnes, Norway or Excalibur; Lode, Groningen, The Netherlands), walking, and aqua jogging. All exercises were executed at a low intensity ( $\left.40 \% \mathrm{~V}_{2} \max \right)$. Every 3 months, a maximal aerobic capacity test was performed, and exercise intensity was corrected if necessary. Heart rate corresponding to $40 \% \dot{\mathrm{V}}_{2}$ max was determined from these tests and was used as the training heart rate. Heart rate was monitored continuously during the training sessions (Polar Electro, Oy, Finland). Subjects attendance at the training sessions was recorded and the trainer inquired for the extra exercise at home regularly.

\section{Body Composition}

Body weight was measured on a digital balance accurate to $0.1 \mathrm{~kg}$ (Sauter D-7470, Ebingen, Germany). Height was measured to the nearest $0.1 \mathrm{~cm}$ using a wall-mounted stadiometer (Seca, model 220, Hamburg, Germany). BMI was calculated from weight and height $\left(\mathrm{kg} / \mathrm{m}^{2}\right)$. Body density was measured by hydrostatic weighing, with a correction for residual lung volume estimated by helium dilution with a spirometer (Volugraph 2000, Mijnhardt, The Netherlands) at the moment of under water weighing. Body composition was calculated according to the formula of Siri. ${ }^{18}$

\section{Maximal Aerobic Capacity}

$\dot{\mathrm{V}}_{2}$ max for each subject was determined by an incremental cycling exercise test on an electromagnetically braked cycle ergometer (Excalibur, Lode). After a warming up period of 5 minutes at $80 \mathrm{~W}$, workload was increased every 4 minutes by $40 \mathrm{~W}$ until exhaustion. During the experiment, ventilatory and gas exchange responses were measured continuously using indirect calorimetry (Oxycon $\beta$; Mijnhardt, Bunnik, The Netherlands). Heart rate was recorded continuously by electrocardiography. The highest oxygen uptake over 30 seconds achieved was taken as $\dot{\mathrm{V}}_{2}$ max.

\section{Physical Activity}

Habitual physical activity was estimated by the Baecke questionnaire, ${ }^{19}$ which is subdivided into physical activity at work, sport during leisure time, and physical activity during leisure time excluding sport.

\section{Energy and Substrate Metabolism}

Energy and substrate metabolism at rest and during exercise was determined at the beginning and the end of the 40-week follow-up period. Experiments were performed 36 to 65 hours after the last exercise bout in a room with a temperature between $23{ }^{\circ} \mathrm{C}$ and $25{ }^{\circ} \mathrm{C}$. After an overnight fast, subjects came to the laboratory by car or public transport to minimize physical activity. A catheter was inserted in an arm vein for blood sampling. Subjects remained in semisupine position on a bed for 30 minutes and subsequently cycled on an ergometer (Excalibur, Lode) for 45 minutes at $50 \%$ of $\dot{\mathrm{V}}_{2}$ max, determined by a maximal aerobic capacity test before the weight reduction period. Absolute workload was kept the same in the pre- and postfollow-up test and was $89 \pm 11 \mathrm{~W}$ in the $\mathrm{C}$ group and $92 \pm 17 \mathrm{~W}$ in the $\mathrm{E}$ group. After cycling, subjects recovered in semisupine position on a bed for 15 minutes. During the experiment $\mathrm{CO}_{2}$ production, $\mathrm{O}_{2}$ consumption, and RER were determined by an open circuit ventilated hood system at rest and recovery (Oxycon $\beta$, Mijnhardt). During exercise, a mouthpiece was used, and for subjects' convenience, measurements were only conducted from $t=10$ to 15,25 to 30 , and 40 to 45 minutes. Energy expenditure was calculated according to the formula of Weir. ${ }^{20}$ The accuracy of the system for measurements of $\mathrm{CO}_{2}$ production and $\mathrm{O}_{2}$ consumption was tested regularly to be within 5\%. During the experiment, heart rate was recorded continuously by electrocardiography. Blood was sampled after 30 minutes of rest $(t=0)$, after 5, 15, 30, and 45 minutes cycling and after 15 minutes recovery. The sample was divided into EDTA or $300 \mu \mathrm{L}$ glutathion ( $45 \mu \mathrm{g} / \mathrm{L}$ saline) plus heparin containing chilled $10-\mathrm{mL}$ tubes and immediately centrifuged at $800 \times$ $g$ for 10 minutes at $4^{\circ} \mathrm{C}$. Plasma was stored at $-80^{\circ} \mathrm{C}$ until analyses. The EDTA containing blood was used for analyses of plasma glucose, free fatty acid (FFA), insulin, glycerol, and lactate concentrations. The heparin and glutathion containing blood was used for analyses of plasma epinephrine and norepinephrine concentrations.

\section{$\beta$-Adrenoceptor-Mediated Energy and Substrate Metabolism}

The same experiment as described above was conducted on another day with infusion of the nonselective $\beta$-antagonist propranolol (PRP) (Zeneca, Ridderkerk, The Netherlands). An extra catheter was inserted in a vein of the contralateral arm for PRP infusion. PRP was infused by a Harvard syringe pump at a dose of $0.71 \mu \mathrm{g} \mathrm{kg}$ fat-free mass $^{-1} \cdot \min ^{-1}$ with a prime of $229.4 \mu \mathrm{g} / \mathrm{kg}$ fat-free mass, which was administered in at least 10 minutes. During the experiment, blood pressure was measured every 10 minutes (Omron $\beta$, Cemex, Nieuwegein, The Netherlands) and heart rate continuously by electrocardiography. Infusion was stopped when the heart rate reached $45 \mathrm{bpm}$. The tests with and without PRP infusion were performed in random order.

\section{Biochemical Analysis}

Plasma concentrations of FFA (NEFA C kit; Wako Chemicals, Neuss, Germany), glucose (GLUC HK kit; Hoffmann-La Roche, Basel, Switzerland), glycerol (Glycerol kit; Boehringer, Mannheim, Germany), and lactate ${ }^{21}$ were measured on a COBAS FARA centrifugal spectrophotometer (Roche Diagnostica, Basel, Switzerland). Plasma insulin concentrations were measured with a double-antibody radioimmunoassay (Insulin RIA 100; Pharmacia, Uppsala, Sweden). Plasma epinephrine and norepinephrine concentrations for the test without PRP infusion were analyzed by high-performance liquid chromatography (HPLC) with electrochemical detection. ${ }^{22}$ 
Table 1. Subject Characteristics at Baseline, Postdiet, and the Change During Follow-up Period of 40 Weeks in the Control and Exercise Groups

\begin{tabular}{|c|c|c|c|c|c|c|}
\hline & \multicolumn{3}{|c|}{ Control Group } & \multicolumn{3}{|c|}{ Exercise Group } \\
\hline & $\begin{array}{l}\text { Baseline } \\
(n=15)\end{array}$ & $\begin{array}{l}\text { Postdiet } \\
(n=15)\end{array}$ & $\begin{array}{c}\Delta \\
\text { Follow-up }\end{array}$ & $\begin{array}{l}\text { Baseline } \\
(n=14)\end{array}$ & $\begin{array}{l}\text { Postdiet } \\
(\mathrm{n}=14)\end{array}$ & $\begin{array}{c}\Delta \\
\text { Follow-up }\end{array}$ \\
\hline Body weight (kg) & $103.6 \pm 11.7$ & $88.2 \pm 9.6$ & $7.1 \pm 4.6$ & $102.6 \pm 9.8$ & $87.8 \pm 7.1$ & $8.9 \pm 4.3$ \\
\hline BMI $\left(\mathrm{kg} \mathrm{m}^{-2}\right)$ & $32.0 \pm 2.2$ & $27.3 \pm 1.8$ & $2.3 \pm 1.5$ & $32.1 \pm 2.6$ & $27.5 \pm 2.2$ & $2.8 \pm 1.4$ \\
\hline Body fat (\%) & $34.1 \pm 4.4$ & $24.9 \pm 5.1$ & $3.5 \pm 2.6$ & $32.7 \pm 3.8$ & $23.8 \pm 4.1$ & $3.9 \pm 4.2$ \\
\hline Fat mass $(\mathrm{kg})$ & $35.2 \pm 5.6$ & $22.0 \pm 5.1$ & $5.3 \pm 3.5$ & $33.7 \pm 6.2$ & $21.0 \pm 4.5$ & $6.0 \pm 5.0$ \\
\hline $\begin{array}{l}\dot{\mathrm{V}}_{2} \max (\mathrm{mL} \\
\left.\min ^{-1}\right)\end{array}$ & $3,025 \pm 370$ & $2,962 \pm 398$ & $109 \pm 305$ & $3,011 \pm 441$ & $2,950 \pm 367$ & $246 \pm 233$ \\
\hline $\begin{array}{c}\dot{\mathrm{V}}_{2} \max / \mathrm{FFM}(\mathrm{mL} \\
\left.\min ^{-1} \mathrm{~kg}^{-1}\right)\end{array}$ & $44.7 \pm 5.5$ & $45.1 \pm 6.3$ & $0.1 \pm 5.1$ & $43.7 \pm 5.1$ & $44.2 \pm 3.9$ & $1.8 \pm 3.4$ \\
\hline
\end{tabular}

NOTE. Data are expressed as means \pm SD.

Abbreviation: FFM, fat-free mass.

\section{Statistical Analysis}

Data are expressed as means $\pm \mathrm{SD}$. Because fat-free mass increased significantly over the follow-up period in both groups, data on energy expenditure were corrected for individual changes in fat-free mass according to the method described by Ravussin et al. ${ }^{23}$ Subject characteristics at the beginning of the follow-up period were tested for differences between groups with an unpaired $t$ test. Changes in subject characteristics over the follow-up period were tested with a 2-way repeated-measurement analysis of variance ANOVA (time $\times$ group). Pearson correlations were calculated in the exercise group between training hours and regain of body weight. Values measured before and after follow-up of the rest, exercise, and recovery periods within the control and exercise groups were compared by a 2-way repeatedmeasurement ANOVA (time and time $\times$ condition). Posthoc testing was performed by a paired $t$ test over the rest, exercise (mean, $\mathrm{t}=15$, 30 , and 45 minutes) and recovery period. $P$ values of the posthoc comparisons were corrected according to Bonferroni inequalities.

Measurements of RER, energy expenditure, and plasma variables before the follow-up period between groups were tested by a 2-way repeated-measurement ANOVA (group and group $\times$ condition). To compare the effects of exercise training on the measured parameters, changes over the follow-up period were calculated for the rest, exercise (average, $\mathrm{t}=15,30$, and 45 minutes), and recovery period. A 2-way repeated-measurement ANOVA was used to test differences between the control and exercise group (group and group $\times$ condition). Areas under the curve (AUC) of the RER versus time graph were calculated, and differences between groups were tested by a 2-way repeatedmeasurement ANOVA (time and time $\times$ group). A $P$ value $<.05$ was considered statistically significant.

\section{RESULTS}

\section{Subject Characteristics}

At the end of the diet period, subject characteristics were not significantly different between groups. Over the follow-up period, body weight, BMI, fat percentage, fat mass, and fat-free mass increased significantly in both groups without differences between groups (2-way ANOVA; group NS, time $P<.0001$, time $\times$ group $\mathrm{NS}$ ). $\dot{\mathrm{V}}_{2}$ max increased significantly over the follow-up period without differences between groups (2-way ANOVA; group NS, time $P<.01$, time $\times$ group, NS). $\dot{\mathrm{V}}_{2} \mathrm{max} / \mathrm{FFM}$ did not change over the follow-up period (Table 1). Subjects in the exercise group attended $57 \% \pm 20 \%$ of the exercise sessions at the laboratory during the follow-up period (4 subjects attended more than $75 \%$ and 1 subject attended less than $25 \%$ of the training sessions). Causes for absence at exercise training sessions were illness, holidays, and work responsibilities. Subjects who could not attend a training session at the laboratory due to work responsibilities reported exercising at home for 1 hour. They received a heart rate monitor to check training intensity by themselves. Because we could not check whether subjects trained at home or not, training sessions at home were not registered. Energy expenditure per training session was estimated to be $1.5 \pm 0.2 \mathrm{MJ}$. Attendance at exercise training sessions was negatively correlated with regain of body weight $(r=-.6 ; P<.05$; regain $[\mathrm{kg}]$ $=-0.1 *$ exercise training during follow-up $[\mathrm{h}]+15.8)$.

The score for sport activity during leisure time (including exercise training at laboratory in the E group) derived from the Baecke Questionnaire was significantly higher in the E group compared with the $\mathrm{C}$ group and did not change over the follow-up period (2-way ANOVA; group $P<.01$, time NS, group $\times$ time, NS) (changed from $2.29 \pm 0.55$ to $2.25 \pm 0.59$ in the $\mathrm{C}$ group and from $2.98 \pm 0.68$ to $3.09 \pm 0.80$ in the $\mathrm{E}$ group). Physical activity during leisure time, excluding sport, was not different between groups and did not change over the follow-up period in both groups (changed from $2.59 \pm 0.46$ to $2.64 \pm 0.53$ in the $\mathrm{C}$ group and from $2.95 \pm 0.75$ to $3.16 \pm$ 0.67 in the $\mathrm{E}$ group).

\section{Effects of Exercise Training During Follow-up on Energy and Substrate Metabolism}

At the beginning of the follow-up period, energy expenditure adjusted for differences in fat free mass (EE adj FFM) and RER were not significantly different between the control and exercise group. EE adj FFM and RER did not change over the follow-up period in the $\mathrm{C}$ and $\mathrm{E}$ group and changes were not significantly different between the groups (Figs 1 and 2, respectively). AUC of RER was not different after the follow-up period from before in both groups (Fig 3). However, RER after follow-up in the $\mathrm{C}$ group tended to be higher than baseline (2-way ANOVA; time $P=.09$, time $\times$ condition, NS). Heart rates at rest, exercise, and recovery were 

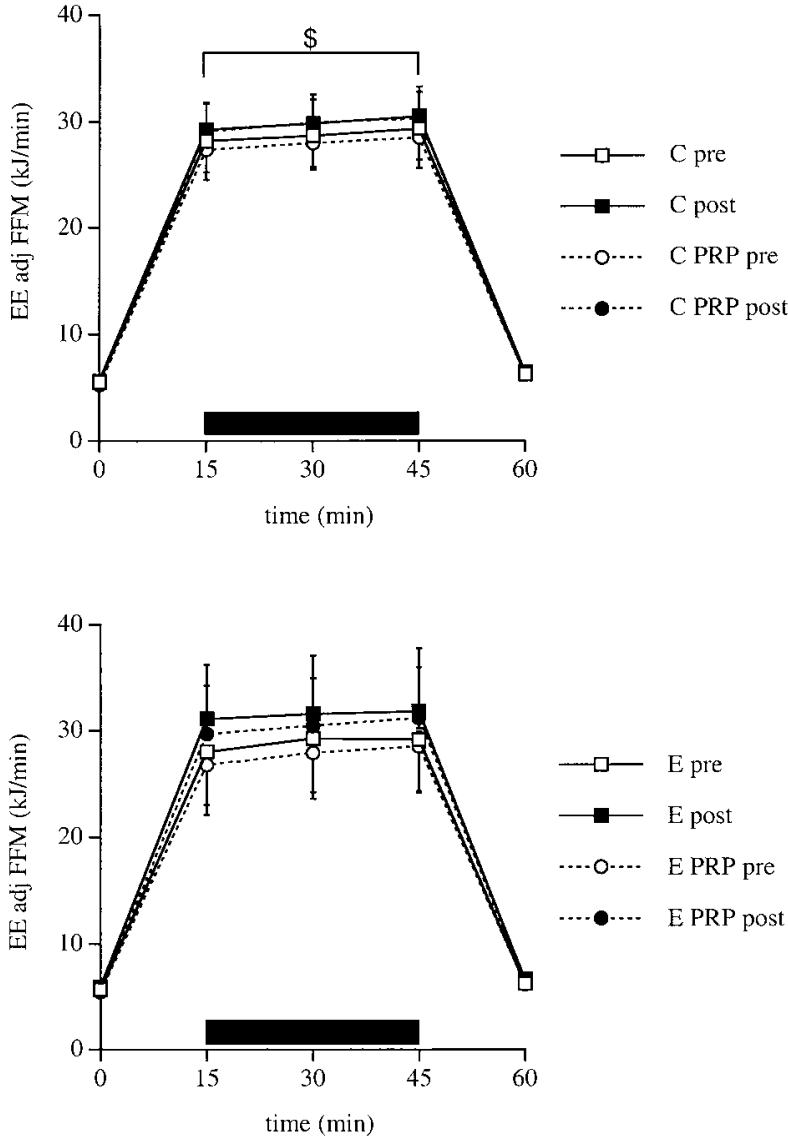

Fig 1. Energy expenditure (EE) ( $\mathrm{kJ} / \mathrm{min}$ ) adjusted for changes in FFM in the control (C) and exercise (E) group pre and post-follow-up, at rest $(t=0)$, during exercise ( $t=15$ to 45 ; black bar), and recovery $(t=60)$ with propranolol (PRP) and without PRP administration. Test with PRP: C group: 2-way ANOVA; time $P<.05$, time $\times$ condition, $P<$ .05. $\$$ intervention effect: post-PRP test significantly different from pre-PRP test, $P<.05$ (average $=15,30$, and 45).
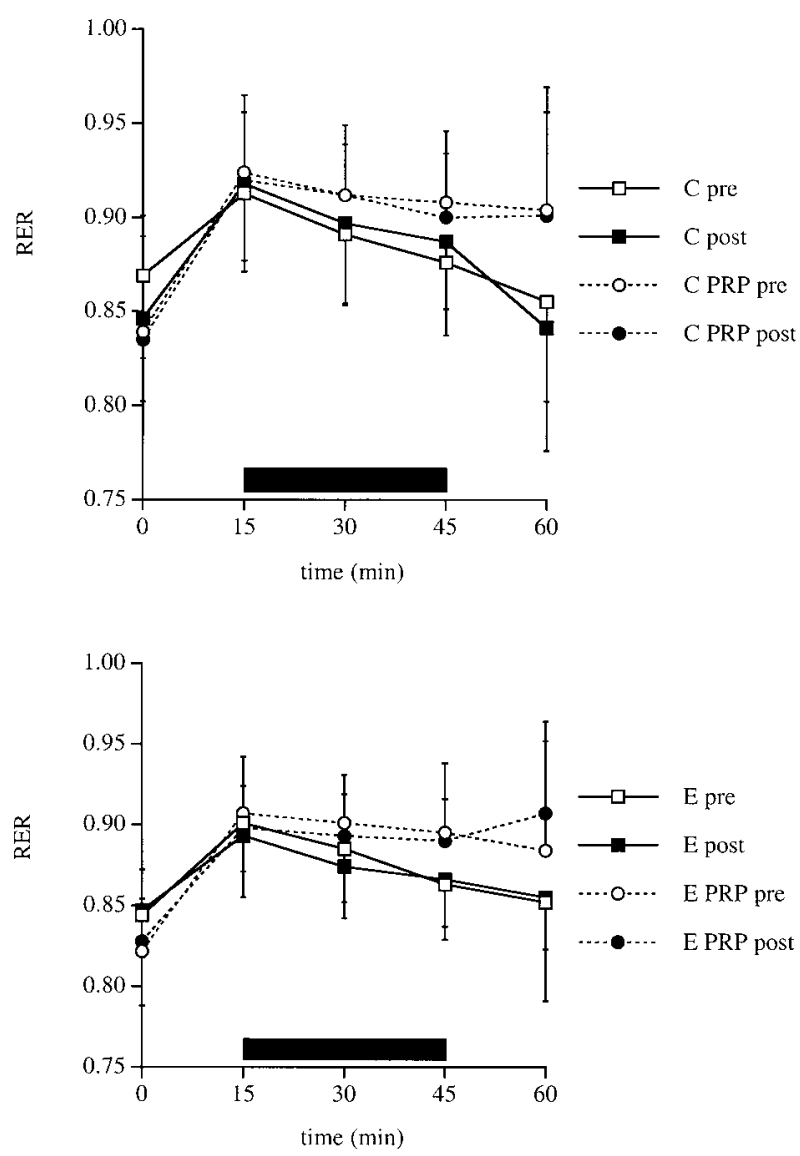

Fig 2. RER in the control (C) and exercise (E) group pre and post-follow-up, at rest $(t=0)$, during exercise ( $t=15$ to 45 ; black bar), and recovery $(t=60)$ with PRP and without PRP administration. Post-follow-up test with PRP different from test without PRP: E group: 2-way ANOVA; time $P<.05$, time $\times$ condition, $P<.0001$.
RER without PRP infusion

Ð PRP-mediated change in RER

E

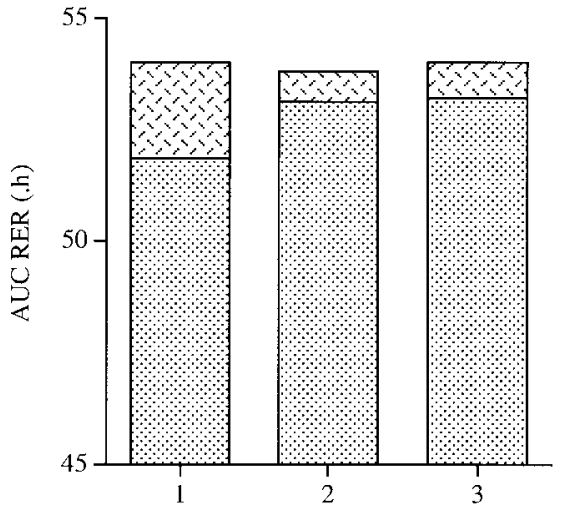

test

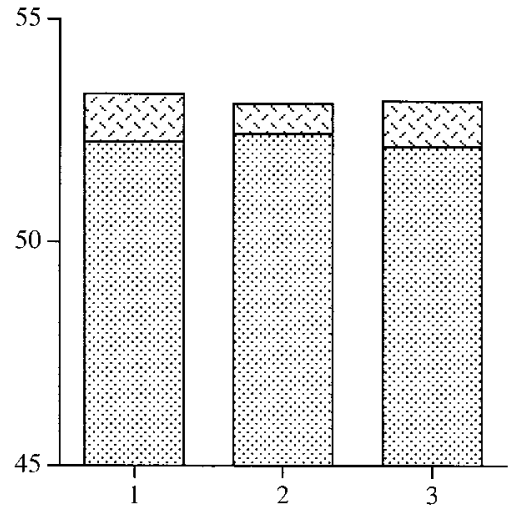

test
Fig 3. Area under the curve (AUC) for RER (h) in the control (C) and exercise (E) group at baseline (1), pre-follow-up (postdiet), (2) post-follow-up, and (3) with and without PRP administration. 
A
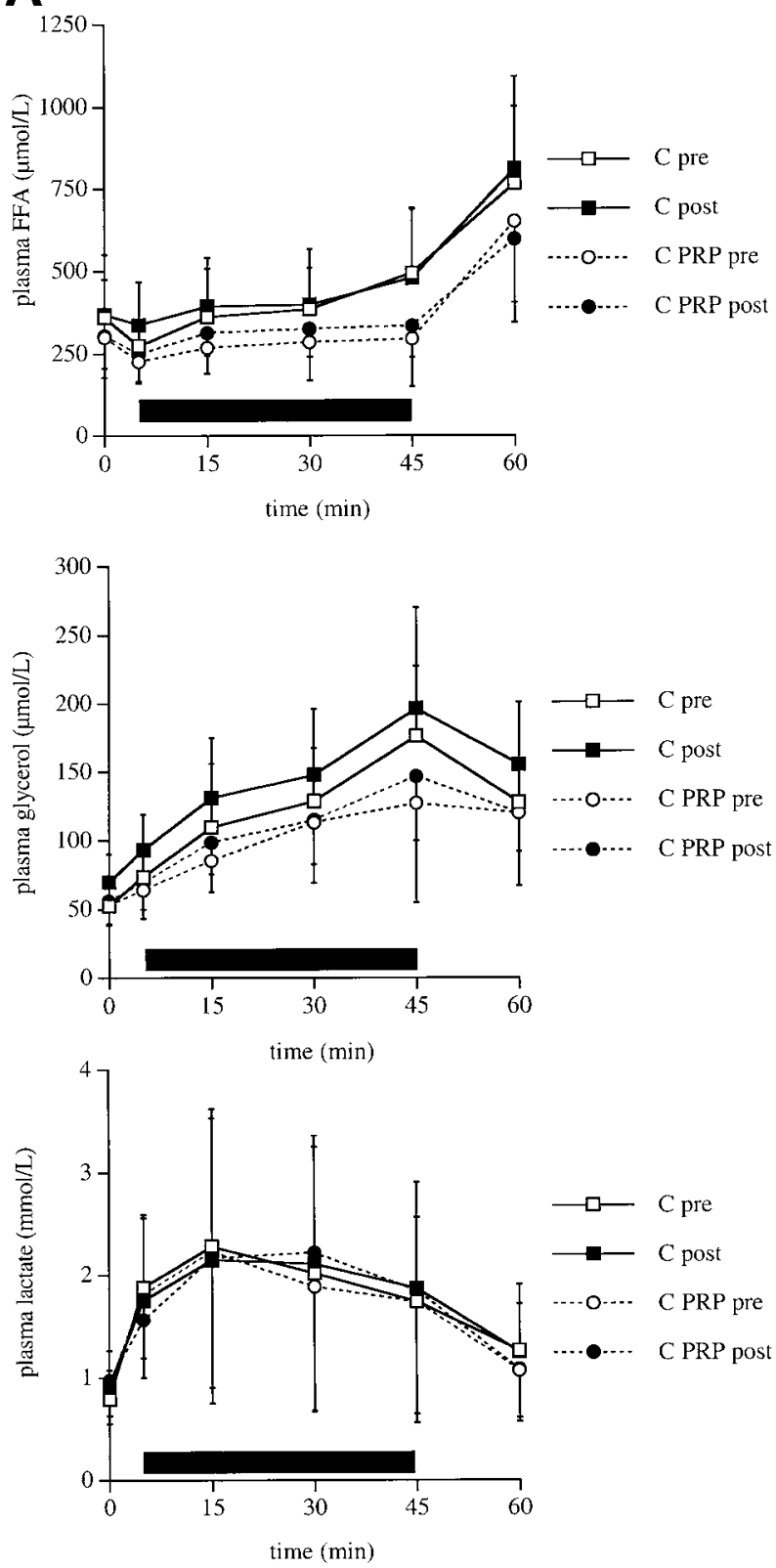
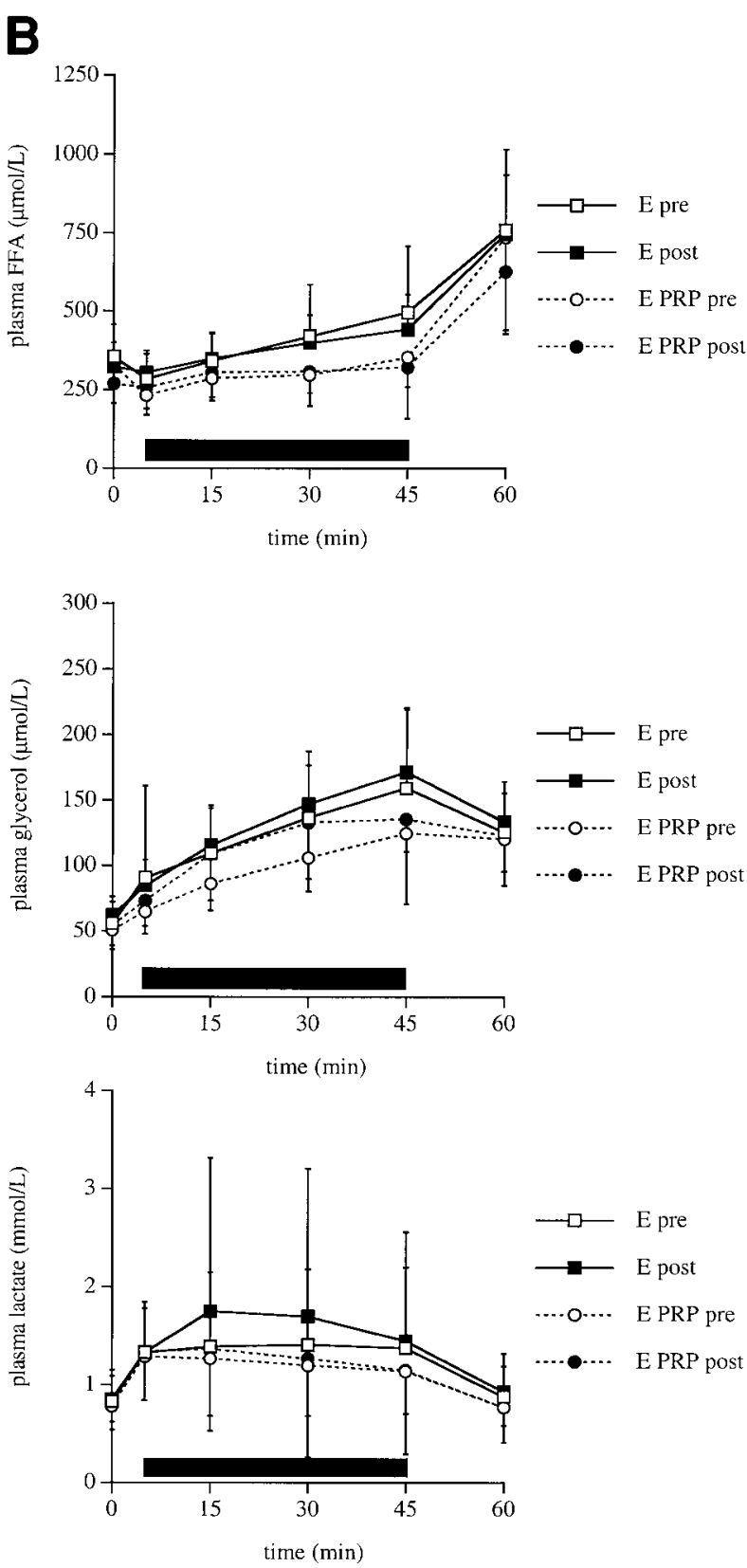

Fig 4. Plasma concentrations of FFA ( $\mu \mathrm{mol} / \mathrm{L})$, glycerol ( $\mu \mathrm{mol} / \mathrm{L})$, and lactate $(\mathrm{mmol} / \mathrm{L})$ in the (A) control (C) group and (B) exercise (E) group pre- and post-follow-up at rest $(t=0)$, during exercise $(t=5$ to 45 ; black bar), and recovery $(t=60)$ with PRP and without PRP administration. FFA: Pre-follow-up test with PRP different from test without PRP, 2-way ANOVA; C group: time $P<.05$, time $\times$ condition, NS. Post-follow-up test with PRP significantly different from test without PRP, 2-way ANOVA; C group: time $P<.05$, time $\times$ condition, $P<.01$; E group: time $P<$ .05 , time $\times$ condition, NS. Glycerol: Post-follow-up test with PRP significantly different from test without PRP, 2-way ANOVA; C group: time, $P<.01$, time $\times$ condition, NS.

$62 \pm 7,120 \pm 16$, and $75 \pm 10 \mathrm{bpm}$ in the $\mathrm{C}$ group and $60 \pm$ $7,111 \pm 9$, and $68 \pm 10 \mathrm{bpm}$ in the E group pre-follow-up (NS between groups). During the follow-up period, heart rates did not change in either group. Pre-follow-up plasma concentrations of FFA, glucose, glycerol, insulin, epinephrine, and norepinephrine were not significantly different between the control and exercise group, but the lactate concentration was significantly lower in the exercise group compared with the control group (2-way ANOVA; group $P=.05$, group $\times$ condition $P<.05)$. Plasma concentrations of FFA, glycerol, and lactate in the control (Fig 4A) and exercise group (Fig 4B) and insulin and epinephrine (Table 2) did not change significantly over the follow-up period. Plasma glucose concentration at rest, exercise, and recovery was significantly increased after the follow-up period in the exercise group (2-way ANOVA; time $P<.05$, time $\times$ 
Table 2. Plasma insulin, Glucose, Epinephrine, and Norepinephrine Pre- and Post-Follow-up of 40 Weeks After Weight Reduction in the Control and Exercise Groups at Rest, After 45 minutes exercise, and 15 minutes Recovery

\begin{tabular}{|c|c|c|c|c|c|c|}
\hline & & Rest & Exercise & Recovery & $\begin{array}{c}\text { 2-way ANOVA } \\
\text { (time) }\end{array}$ & $\begin{array}{c}\text { 2-way ANOVA } \\
\text { (time } \times \text { condition) }\end{array}$ \\
\hline \multicolumn{7}{|c|}{ Insulin $(\mu \mathrm{u} / \mathrm{mL})$} \\
\hline \multirow[t]{2}{*}{ C } & Pre & $8.9 \pm 2.5$ & $7.5 \pm 2.5$ & $9.7 \pm 2.8$ & NS & NS \\
\hline & Post & $9.6 \pm 4.5$ & $6.6 \pm 2.0$ & $11.0 \pm 4.9$ & & \\
\hline \multirow[t]{2}{*}{$E$} & Pre & $9.0 \pm 4.2$ & $6.9 \pm 3.2$ & $10.3 \pm 4.7$ & NS & NS \\
\hline & Post & $10.8 \pm 4.6$ & $8.0 \pm 2.7$ & $12.5 \pm 5.3$ & & \\
\hline \multicolumn{7}{|c|}{ Glucose (mmol/L) } \\
\hline \multirow[t]{2}{*}{$\mathrm{C}$} & Pre & $5.11 \pm 0.42$ & $4.78 \pm 0.38$ & $4.80 \pm 0.65$ & NS & NS \\
\hline & Post & $5.27 \pm 0.43$ & $4.91 \pm 0.42$ & $5.09 \pm 0.44$ & & \\
\hline \multirow[t]{2}{*}{$E$} & Pre & $5.05 \pm 0.34$ & $4.75 \pm 0.34$ & $4.91 \pm 0.39$ & $P<.05$ & NS \\
\hline & Post & $5.17 \pm 0.39$ & $4.99 \pm 0.32$ & $5.15 \pm 0.40$ & & \\
\hline \multicolumn{7}{|c|}{ Epi (ng/L) } \\
\hline \multirow[t]{2}{*}{$\mathrm{C}$} & Pre & $31 \pm 21$ & $93 \pm 43$ & $36 \pm 17$ & NS & NS \\
\hline & Post & $34 \pm 25$ & $102 \pm 40$ & $45 \pm 24$ & & \\
\hline \multirow[t]{2}{*}{$E$} & Pre & $29 \pm 16$ & $98 \pm 42$ & $36 \pm 15$ & NS & NS \\
\hline & Post & $30 \pm 13$ & $92 \pm 37$ & $46 \pm 20$ & & \\
\hline \multicolumn{7}{|c|}{ Norepi (ng/L) } \\
\hline \multirow[t]{2}{*}{$\mathrm{C}$} & Pre & $340 \pm 126$ & $901 \pm 212$ & $404 \pm 153$ & $P<.0001$ & $P<.01$ \\
\hline & Post & $479 \pm 145^{*}$ & $1,254 \pm 168 *$ & $618 \pm 147^{*}$ & & \\
\hline \multirow[t]{2}{*}{$E$} & Pre & $356 \pm 130$ & $746 \pm 269$ & $385 \pm 134$ & $P<.01$ & $P<.01$ \\
\hline & Post & $553 \pm 158^{*}$ & $1,183 \pm 367^{*}$ & $628 \pm 268^{*}$ & & \\
\hline
\end{tabular}

NOTE. Data are expressed as means \pm SD

Abbreviations: Epi, epinephrine; Norepi, norepinephrine; C, control; E, exercise; NS, not significant.

*Significantly different from pre-follow-up, $P \leq .001$.

condition, NS), while the change was not statistically significant in the $\mathrm{C}$ group (Table 2). Plasma norepinephrine concentration increased significantly in both groups over the follow-up period during rest, exercise, and recovery (2-way ANOVA; time $P<.01$, time $\times$ condition $P<.01$ ) (Table 2 ). None of the changes were significantly different between groups.

\section{Effects of Exercise Training During Follow-up on} $\beta$-Adrenoceptor-Mediated Substrate Metabolism

Pre-follow-up, energy expenditure, RER, heart rate, and measured plasma variables during PRP infusion did not differ significantly between groups. PRP infusion did not affect energy expenditure. Energy expenditure with PRP infusion was significantly higher after the follow-up period compared with before in the $\mathrm{C}$ group (2-way ANOVA; time $P<.05$, time $\times$ condition $P<.05$ ), but not in the E group (Fig 1). PRP infusion increased RER significantly in the E group after the follow-up period (2-way ANOVA; time $P<.05$, time $\times$ condition $P<$ .0001) (Fig 2). The PRP-mediated change in RER (expressed as AUC of RER) was not significantly different before and after the follow-up period in either groups (Fig 3). PRP infusion significantly decreased heart rate (2-way ANOVA; time $P<.001$, time $\times$ condition $P<.001)$ during rest, exercise, and recovery in both groups (C: $-9 \pm 5,-24 \pm 11$, and $-15 \pm 7$ bpm; E group: $-5 \pm 5,-20 \pm 12$, and $-9 \pm 5 \mathrm{bpm})$, and the effect was not different after follow-up. The effect of PRP infusion on plasma FFA, glucose (data not shown), glycerol, and lactate was not significantly different after compared with before follow-up (Fig 4A and B). PRP infusion decreased plasma FFA concentration in the $\mathrm{C}$ group before and after follow-up (2-way ANOVA; time $P<$ .05 ) and in the E group after follow-up (2-way ANOVA; time $P<$ $.05)$. Plasma glycerol concentration decreased significantly in the
C group due to PRP infusion after follow-up (2-way ANOVA; time $P<.01)$. PRP infusion did not affect plasma lactate and glucose concentration.

\section{DISCUSSION}

The present study demonstrated that continuation of a lowintensity exercise training program $\left(40 \% \dot{\mathrm{V}}_{2} \max \right)$ over a follow-up period of 40 weeks after weight reduction, with an average adherence rate of $57 \% \pm 20 \%$, did not limit body weight regain. Relative fat oxidation and energy expenditure, as well as the contribution of the sympathetic nervous system to relative fat oxidation, were maintained at postdiet level over the follow-up period.

The present study showed that training attendance was negatively correlated with body weight regain $(r=-.6 ; P<.05)$. From the regression equation, it can be predicted that if exercise training is performed 3 times a week as compared with once a week during the follow-up period, average body weight regain would be $4 \mathrm{~kg}$ instead of $12 \mathrm{~kg}$. This suggests that attendance at exercise training sessions is a very important factor in a better weight maintenance success. However, regain of body weight in the control group, without exercise of lowintensity exercise training should be at least 3 times a week to attain meaningful differences in weight regain with nonexercising individuals. It is surprising that the data seem to suggest that weight regain may be larger in subjects with a low attendance to the exercise program than in subjects not attending the exercise program at all (control group). However, it cannot be excluded that some of the subjects in the control group were as active or even more active than some of the subjects with low adherence to the exercise program. Subjects for this study were included if they did not spend more than 2 hours in sports 
activities per week. ${ }^{17}$ Subjects in the control group were asked to maintain their habitual physical activity pattern, but not to refrain from physical activity. In addition, subjects in the exercise group might have compensated for an increase in energy expenditure by an increase in caloric intake or a reduction of energy expenditure postexercise.

During the follow-up period, relative fat oxidation did not change either in the control or in the exercise group. Comparison of the present study with baseline (before the diet period) showed that in the exercise group, RER at the end of the follow-up period was not different from the baseline. On the contrary, in the $\mathrm{C}$ group, RER after follow-up tended to be increased compared with baseline (2-way ANOVA; time $P=$ .09). Changes in fat mass have been shown to correlate positively with changes in fat oxidation. ${ }^{14}$ Therefore, the increase in fat mass in the control and exercise groups during the follow-up period would have been expected to induce an increase in fat oxidation. However, we failed to detect an increase in fat oxidation during follow-up, and changes in fat oxidation did not correlate with changes in fat mass, but changes may have been too small to detect with the methods used.

Continuation of exercise training during weight maintenance did not affect fat oxidation, which was also reported by Pasman et $\mathrm{al}^{24}$ for fasting RER. It might be suggested that the effect of exercise training on fat oxidation was already complete in the weight loss phase of the study and prevented the weight lossinduced decrease in fat oxidation. Therefore, the most important effect of continuation of exercise training during the follow-up period in trained subjects might be maintenance of fat oxidation at the relatively higher pre-follow-up level compared with the control group, rather than a further increase in fat oxidation.

The present study also showed that the contribution of $\beta$-adrenergic nervous system activity to substrate oxidation was not changed over the follow-up period in both the control and exercise groups. Results of the preceding diet period showed that weight reduction tended to reduce the contribution of $\beta$-adrenergic activity to fat oxidation, but not when exercise training was added to the diet period. ${ }^{17}$ In agreement with the results on fat oxidation, the results of the present study also suggest that the effect of exercise training on $\beta$-adrenergic nervous system activity was completed in the weight loss phase of the study, and continuation of exercise training during the follow-up period only maintained the reached effect.

Data of the present study of the total group did not indicate a role for low-intensity exercise training as a cornerstone for weight maintenance long term. This is probably not related to the inadequacy of low-intensity exercise training to increase fat oxidation capacity, because it was shown that a similar lowintensity exercise training program was able to increase fat oxidation during exercise in the obese under weight-stable conditions ${ }^{25,26}$ and to prevent the weight loss-induced reduction of fat oxidation during exercise. ${ }^{17}$ On the other hand, Yoshioka et $\mathrm{al}^{27}$ suggest that it is particularly high-intensity exercise that is associated with higher fat oxidation and lower body fat mass, which may be related to their finding that postexercise fat oxidation is stimulated to a larger extent by a high intensity (77\% $\left.\dot{\mathrm{V}}_{2} \mathrm{max}\right)$ exercise bout than by a low-intensity $(37 \%$ $\dot{\mathrm{V}}_{2} \max$ ) exercise bout. However, there are no data on the effects of different exercise training intensities on 24-hour respiratory quotient (RQ), so the question whether 24-hour RQ is affected differently by high- and low-intensity exercise training cannot be answered at this moment. Rather than exercise intensity per se, it may be the total extra energy expenditure associated with exercise that is the factor determining weight maintenance success. Fogelholm et $\mathrm{al}^{10}$ investigated the effects of walking on weight maintenance in obese women. Even in the group who exercised 4 to 6 hours a week (weekly energy expenditure during physical activity, 7.7 MJ), weight maintenance was not improved compared with the non-exercising group. ${ }^{10}$ This was in contrast to a study by Ewbank et al ${ }^{9}$ showing that the total energy expenditure used for physical activity estimated from the Harvard Alumni Physical Activity Survey Questionnaire predicted weight loss and percentage regain. Schoeller et $a^{28}$ also showed that the Physical Activity Index is a predictor of weight and fat gain. They showed that there is a threshold of physical activity for minimizing weight gain of $47 \mathrm{~kJ}$ per $\mathrm{kg}$ body weight/d. This threshold corresponded to $80 \mathrm{~min} / \mathrm{d}$ of moderate-intensity physical activity or $35 \mathrm{~min} / \mathrm{d}$ of vigorous physical activity. In the present study, energy expenditure for exercise training during the follow-up period at the laboratory was $4.1 \pm 1.7 \mathrm{~kJ} / \mathrm{kg}$ body weight $/ \mathrm{d}$ (range, 0.9 to $6.2 \mathrm{~kJ}$ ). This suggests that in order to increase energy expenditure by low-intensity exercise training $(40 \%$ $\dot{\mathrm{V}}_{2} \max$ ) to $47 \mathrm{~kJ} / \mathrm{kg}$ body weight/d, the subjects should exercise or be physically active approximately $3 \mathrm{~h} / \mathrm{d}$.

In conclusion, the present study showed that continuation of low-intensity exercise training for 40 weeks after weight reduction did not limit regain of body weight in obese men, unless exercise training was frequently performed ( $\geq 3$ times a week). Relative fat oxidation, energy expenditure, and $\beta$-adrenergic-mediated fat oxidation were maintained at postdiet levels whether or not low-intensity exercise training was performed during follow-up. This might indicate that performance of low-intensity exercise training after weight loss can reduce the risk of developing a positive fat balance.

\section{ACKNOWLEDGMENT}

The authors thank Jos Stegen and Joan Senden for analysis of plasma catecholamine and insulin concentrations, respectively, and Carlien Theeuwes and Heidi Ilomaki for assistance during the experiments. Furthermore, we thank the Department of Physiotherapy, Academic Hospital Maastricht, for the availability of the aqua-jogging facilities and Lode for providing the cycle ergometers.

\section{REFERENCES}

1. Kuczmarski RJ, Flegal KM, Campbell SM, et al: Increasing prevalence of overweight among US adults. The National Health and Nutrition Examination Surveys, 1960 to 1991. JAMA 272:205-11, 1994

2. Seidell JC: Obesity in Europe. Obes Res 3:89s-93s, 1995
3. Sikand G, Kondo A, Foreyt JP, et al: Two-year follow-up of patients treated with a very-low-calorie diet and exercise training. J Am Diet Assoc 88:487-488, 1988

4. Van Dale D, Saris WH, ten Hoor F: Weight maintenance and 
resting metabolic rate $18-40$ months after a diet/exercise treatment. Int J Obes 14:347-359, 1990

5. Froidevaux F, Schutz Y, Christin L, et al: Energy expenditure in obese women before and during weight loss, after refeeding, and in the weight-relapse period. Am J Clin Nutr 57:35-42, 1993

6. Hensrud DD, Weinsier RL, Darnell BE, et al: A prospective study of weight maintenance in obese subjects reduced to normal body weight without weight-loss training. Am J Clin Nutr 60:688694, 1994

7. Pronk NP, Wing RR: Physical activity and long-term maintenance of weight loss. Obes Res 2:587-599, 1994

8. Miller WC, Koceja DM, Hamilton EJ: A meta-analysis of the past 25 years of weight loss research using diet, exercise or diet plus exercise intervention. Int J Obes 21:941-947, 1997

9. Ewbank PP, Darga LL, Lucas CP: Physical activity as a predictor of weight maintenance in previously obese subjects. Obes Res 3:257263, 1995

10. Fogelholm M, Kukkonen-Harjula K, Oja P: Eating control and physical activity as determinants of short-term weight maintenance after a very-low-calorie diet among obese women. Int J Obes 23:203210, 1999

11. Nicklas BJ, Rogus EM, Goldberg AP: Exercise blunts declines in lipolysis and fat oxidation after dietary-induced weight loss in obese older women. Am J Physiol 273:E149-155, 1997

12. Pasman WJ, Westerterp-Plantenga MS, Saris WHM: The effect of exercise training on leptin levels in obese males. Am J Physiol 274:E280-E286, 1998

13. Wood PD, Stefanick ML, Williams PD, et al: The effects on plasma lipoproteins of a prudent weight-reducing diet with or without exercise, in overweight men and women. N Engl J Med 325:461-466, 1991

14. Schutz Y, Tremblay A, Weinsier RL, et al: Role of fat oxidation in the long-term stabilization of body weight in obese women. Am J Clin Nutr 55:670-674, 1992

15. Astrup A, Buemann B, Gluud C, et al: Prognostic markers for diet-induced weight loss in obese women. Int J Obes 19:275-278, 1995
16. Ravussin E, Swinburn BA: Metabolic predictors of obesity: Cross-sectional versus longitudinal data. Int J Obes 17:S41-42, 1993

17. Van Aggel-Leijssen DP, Saris WM, Hul GB, et al: Short term effects of weight loss with or without low intensity exercise training on fat metabolism in obese men. Am J Clin Nutr 73:523-531, 2001

18. Siri WE: The gross composition of the body. Adv Biol Med Physiol 4:239-280, 1956

19. Baecke JA, Burema J, Frijters JE: A short questionnaire for the measurement of habitual physical activity in epidemiological studies. Am J Clin Nutr 36:936-942, 1982

20. Weir JB: New methods for calculating metabolic rate with special reference to protein metabolism. J Physiol 109:1-9, 1949

21. Gutmann I, Wahlefeld AW: L- $(+)$-Lactate, determination with lactate dehydrogenase and NAD, in Bergmeyer HU (ed): Methods in Enzymatic Analysis (ed 2). New York, NY, Academic, 1974, pp 1464-1468

22. Smedes F, Kraak JC, Poppe H: Simple and fast solvent extraction system for selective and quantitative isolation of adrenaline, noradrenaline and dopamine from plasma and urine. J Chromatogr 231: 25-39, 1982

23. Ravussin E, Bogardus C: Relationship of genetics, age, and physical fitness to daily energy expenditure and fuel utilization. Am J Clin Nutr 49:968-975, 1989

24. Pasman WJ, Westerterp-Plantenga MS, Saris WHM: The effect of body weight changes and endurance training on $24 \mathrm{~h}$ substrate oxidation. Int J Obes 23:1223-1232, 1999

25. Van Aggel-Leijssen DPC, Saris WHM, Wagenmakers AJ, et al: The effect of low intensity exercise training on fat oxidation of obese women. Obes Res 9:86-96, 2001

26. Van Aggel-Leijssen DP, Saris WH, Wagenmakers AJ, et al: The effect of exercise training at different intensities on fat metabolism of obese men. J Appl Physiol 92:1300-1309, 2002

27. Yoshioka M, Doucet E, St-Pierre S, et al: Impact of highintensity exercise on energy expenditure, lipid oxidation and body fatness. Int J Obes 25:332-339, 2001

28. Schoeller DA, Shay K, Fushner RF: How much physical activity is needed to minimize weight gain in previously obese women? Am J Clin Nutr 66:551-556, 1997 